www.jmscr.igmpublication.org

Index Copernicus Value: 79.54

ISSN (e)-2347-176x ISSN (p) 2455-0450

crossref DOI: https://dx.doi.org/10.18535/jmscr/v7i6.188

\title{
External Ophthalmomyiasis Presenting as Acute Allergic Conjunctivitis in a Patient Belonging to Urban Population of East India- A Rare Case Report
}

\author{
Authors \\ Dr Matuli Das, Dr Pallavi Priyadarsani Sahu \\ Department of Ophthalmology, Kalinga Institute of Medical Sciences, KIIT University, Bhubaneswar- \\ 751024, Odisha, India \\ *Corresponding Author \\ Dr Pallavi Priyadarsani Sahu \\ Department of Ophthalmology, Kalinga Institute of Medical Sciences, KIIT University, Patia,
} Bhubaneswar-751024, Odisha, India

\begin{abstract}
Ophthalmomyiasis refers to larval infestation of eye. In this report we describe a case of a 20 years old male who presented with chief complaints of pain, redness, foreign body sensation and watering of left eye following fall of foreign body. His BCVA was 20/20 right eye and 20/40 left eye. On slit lamp biomicroscopy motile larva was seen on conjunctiva borrowing into deeper structures on attempts of removal. A total of 14 larva were mechanically removed which was followed by medical management. The larvae were identified as Oestrus ovis (sheep botfly) on microscopy. On subsequent 1 day and 1 week follow up patient's signs and symptoms improved.

Keywords: Ophthalmomyiasis, sheep botfly, allergic conjunctivitis, community ophthalmolgy, case report.
\end{abstract}

\section{Introduction}

Myiasis is a condition in which there is infestation of living or dead tissues of animals and human with larva of certain flies ${ }^{[1]}$. Ocular involvement in myiasis known as ophthalmomyiasis is rare and reported to be around $5 \%^{[2]}$. It can be of two types (a)Ophthalmomyiasis externa-being limited to conjunctiva and (b)interna where there is intraocular penetration ${ }^{[3]}$.

Members of family Oestridae, Calliphoridae, Sarcophagidae are known to cause myiasis out of which Oestrus ovis (sheep botfly) is the most common pathogen causing ophthalmomyiasis in humans ${ }^{[1]}$.
Many cases of ophthalmomyiasis have been reported worldwide ${ }^{[4]}$, but in India very few sporadic cases have been reported till date ${ }^{[5-6]}$. This condition is found to be more prevalent in people living in rural areas, in unhygienic conditions and also in those having history of contact with live stock ${ }^{[1]}$.

Here we report a case of ophthalmomyiasis externa in a healthy adult belonging to an urban area with no history of contact with cattle and also this is the first case being reported from this part of India. 


\section{Case Report}

A 20 years old male presented to us with chief complaints of redness, foreign body sensation, pain and watering of left eye due to fall of foreign body into his eye while he was sitting in the lawn. There was no history of prior treatment and any other systemic illness.

His BCVA was 20/20 RE and 20/40 LE. On slit lamp biomicroscopy there was mild lid oedema. Conjunctiva was congested and chemosed which was more prominent in inferiorly. Mucoiddis charge was present in inferior fornix. On everting upper lid tarsal conjunctiva was normal. Cornea showed multiple epithelial erosions which was fluorescein stain positive.

A drop of $4 \%$ proparacaine was instilled and mucoid discharge was swiped with swab stick following which we observed multiple motile larvae crawling on conjunctiva. The larvae were about $2 \mathrm{~mm}$ in size, translucent with a dark head.(Fig.1)

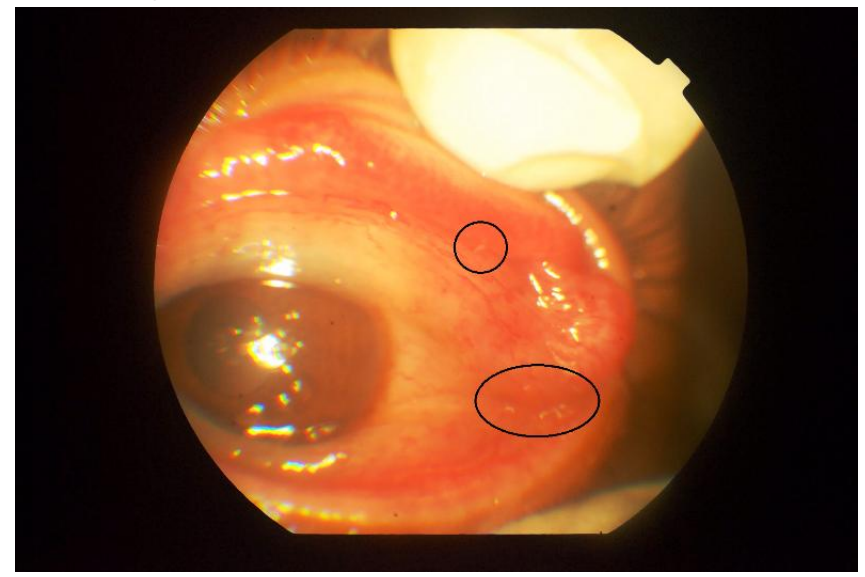

Figure 1: showing multiple motile larva of sheep botfly on conjunctiva and fornices.

On attempted removal with swab stick they were seen burrowing into inferior conjunctival fornix. So they were removed with the help of forceps under topical anaesthesia. A total of 14 larvae were removed and sent to the laboratory for identification. Rest of the anterior segment was normal. Dilated funduscopy with indirect ophthalmoscope revealed normal vitreous and retina. Ocular movements were full in all directions. Based on these findings a diagnosis of ophthalmomyiasis externa presenting as acute allergic keratoconjunctivitis was made.
The patient was prescribed moxifloxacin $0.5 \%$ eye drops 4 hourly, chloramphenicol (10mg) + dexamethasone (1 mg) + polymyxin B (10000 IU) eye ointment twice daily and $0.5 \%$ carboxymethyl cellulose drops 2 hourly. A dose (16mg) of oral ivermectin was also given and patient was called for follow up on next day.

On next day BCVA was 20/20 in both eyes. Lid Oedema and conjunctival congestion had decreased and cornea was clear. B scan was done which was normal. Nasal and aural myiasis was ruled out after ENT examination. On subsequent follow ups during first week patient's BCVA was $20 / 20$ in both eyes and ocular examination was normal.

On microscopy these larvae were found to be segmented with intersegmental bands. A pair of dark brown oral hooks and numerous hooks were present on margins of each body segment as shown in Fig. 2 and Fig.3. Based on these distinct morphological findings they were identified to be larvae of Oestrus ovis.

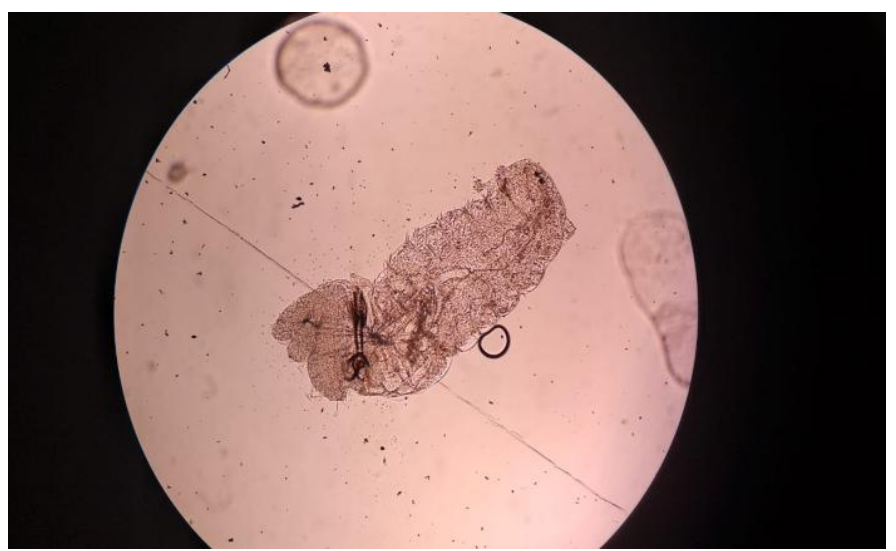

Figure 2: Photograph showing larvae of oestrus ovis under microscope.

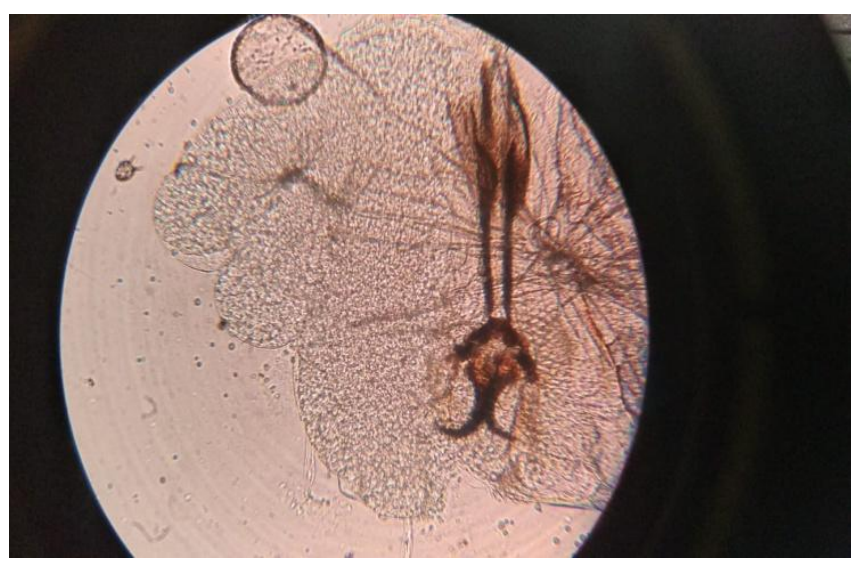

Figure 3: Enlarged view of head part of larva. 


\section{Discussion}

Myiasis in humans can be of six types: dermal and subdermal, facial cavity, wound, gastrointestinal, vaginal and generalized. In humans three species of dipteran flies- Oestridae, Calliphoridae, Sarcophagidae are known to cause myiasis out of which the most common pathogen causing ophthalmomyiasis is Oestrus ovis ${ }^{[1]}$.

Oestrus ovis (sheep botfly) is a widespread species of fly belonging to class: insecta, order: diptera, family oestrideae and genus oestrus ${ }^{[6]}$. It is known for its parasitic predation and damage to sheep, goat, deer, cattle. Human is an accidental host ${ }^{[1][6]}$. In some areas of the world it is a significant pest which affects agriculture economy.

Adult fly of oestrus is a bee like insect $10-12 \mathrm{~mm}$. long, hairy with a banded dark grey body and dull yellow head and legs. The adult female fly is active during summer and early fall. In its normal life cycle the eggs hatch in the vagina of female fly into larvae. The gravid adult female fly swarms around nostrils of sheep and goats and deposits larva. Then the larvae migrate into the sinuses where they undergo three progressive larval developmental stages. Subsequently the third larval (mature) stage is sneezed out of nose and pupate in soil after three or more weeks into adults. Adults have a life span of about 28 days. Direct contact of host with the fly is not necessary for infestation.

Human beings are accidental host and mode of infestation is by spraying of stream of fluid containing first stage larva by the adult female while it is flying in and around eyes of man. But the larva cannot mature further here and survive beyond 8-10 days ${ }^{[7]}$.

Oestrus ovis do not produce proteolytic enzymes so are not capable of deeper penetration so in eye it is mostly limited to conjunctiva and cornea. According to previous reports the ocular involvement ranges from-periorbital lid oedema, follicular conjunctival injection, pseudomembrane formation, epithelial erosions, subepithelial linear opacities, stromal keratitis and uveitis ${ }^{[6]}$. Allergic rhinitis has also been reported. Out of these catarrhal conjunctivitis is the most common presentation, so thorough slit lamp examination under high magnification should be done in all cases as it can be easily misdiagnosed as allergic conjunctivitis, preseptal cellulitis if oedema is generalized and sometimes chalazion if the oedema is localized.

Another species Dermatobiahominis is capable of deeper penetration into sclera and burrow into subretinal space causing iridocyclitis, endophthalmitis and loss of vision. Ocular pruritus is more common due to deposition of larval excretion in fornices ${ }^{[8]}$. As it is difficult to differentiate between different these two species (dermatobia and oestrus) causing myiasis prior to microscopy, so all patients with ocular myiasis should undergo thorough posterior segment evaluation to rule out invasive myiasis for early intervention and better prognosis.

ENT examination should also be done in all cases to rule out nasal and aural myiasis and also allergic rhinitis which have been reported in some cases.

Cases of ophthalmyiasis externa should be treated as follows:

Drops of topical anesthetic should be administered to paralyze the larva followed by manual removal with forceps. Subsequently antibiotic and lubricating eye drops should be administered. Topical steroids in the form of drops and ointment could be used as they are known to decrease inflammation.

A dose of ivermectin has also been found to be useful both for treatment and prophylactic purpose in some previous reports but its role is doubtful. Ideally all patients with ophthalmomyiasis externa should carefully be followed up for at least 8-10 days as this is the reported survival period of larva in human beings. After this period they are known to die on their own.

Though many cases of Oestrus ovis have been reported from India till date where most cases belong to rural areas and people living in poor hygienic conditions, this is the first case being 
reported from Eastern India with the patient from an urban population and with good socioeconomic status.

\section{Conclusion}

Though many cases have been reported, ophthalmomyiasis externa remains to be less commonly known to ophthalmologists and microbiologists, thus posing a diagnostic challenge. Distinct morphology and relevant history might be helpful in some cases. Most cases may be misdiagnosed as conjunctivitis at periphery level as the manifestations are similar and treatment might be delayed. So early slit lamp biomicroscopy and prompt removal of larvae should be done in all cases and patients should be carefully followed up for better outcome.

\section{Acknowledgement}

We would like to thank the Parasitology Division, Centres for Disease Contol, Atlanta, USA for confirming the identification of larvae.

We would also like to thank Department of Microbiology \& ENT Department of KIMS Medical College for their contributions in the process of diagnosis \& treatment.

\section{References}

1. Abdellatif MZ, Elmazar HM, Essa AB. Oestrus ovis as a cause of red eye in Aljabal Algharbi, Libya.Middle East Afr J Ophthalmol 2011;18:305-308.

2. Ziemianski MC, Lee KY, Sabates FN. Ophthalmomyiasisinterna. Arch Ophthalmol. 1980. 98: 1588-1589. PMID: 7191701.

3. Corrin R, Scholten T, Earle J. Ocular myiasis: mobile conjunctival foreign body. Can Med Assoc J 1985;132:1291-2.

4. Amr ZS, Amr BA, Abo-Shehada MN. Ophthalmomyiasis externa caused by Oestrus ovis L. in the Ajloun area of northern Jordan. Ann Trop Med Parasitol 1993;87:259-62.
5. Misra S, Misra N, Reddy B. External ophthalmomyiasis by Oestrus ovis: an unknown endemic eye disease in rural parts of central India. Trop Doct. 2008. 38: 120-122. PMID: 18453513.

6. Sreejith R S, Reddy A K, Ganeshpuri S S, Garg P. Oestrus ovisophthalmomyiasis with keratitis. Indian J Med Microbiol 2010;28:399-402.

7. Verstrynge K, Foets B. External ophthalmomyiasis: A case report. Bull Soc Belge Ophthalmol 2004; 294:67-71.

8. Denion E, Dalens PH, Couppié P, Aznar C, Sainte-Marie D, Carme B, et al. External ophthalmomyiasis caused by Dermatobiahominis. A retrospective study of nine cases and a review of the literature. ActaOphthalmolScand 2004; 82:576-84. 